\title{
Dyke-Davidoff-Masson Syndrome Associated with Epidermoid Tumour and Arachnoid Cyst: A Case Report
}

Güner Menekşe, Kerem Mazhar Özsoy, Tuncay Ateş, Ali İhsan Ökten, Aslan Güzel

Department of Neurosurgery, Adana Numune Training and Research Hospital, Adana, Turkey

\begin{abstract}
Background: Dyke-Davidoff-Masson Syndrome (DDMS) is a rarely seen clinical entity which is characterised by cerebral hemiatrophy, contralateral hemiparesis and epilepsy. Radiological features are typical, such as unilateral atrophy of the cerebral hemisphere and associated compensatory bone changes in the skull, like thickening, enlargement of the paranasal sinuses and mastoid air cells.

Case Report: In this article, we report the first case of DDMS associated with epidermoid tumour and arachnoid cyst, who underwent operation for an epidermoid tumour in the inter-hemispheric region. To our knowledge, this is the first report of DDMS associated with multiple intracranial pathologies and this association has not been previously described in the literature.

Conclusion: Any patient who receives DDMS in the light of clinical and radiological findings should be investigated for concomitant pathologies. Different sequences of MRI may be useful in the diagnosis of other intracranial lesions.
\end{abstract}

Key Words: Arachnoid cyst, Dyke-Davidoff-Masson Syndrome, epidermoid tumour

Received: 16.01.2013

Accepted: 14.06.2013

Available Online Date: 27.09.2013

\section{Introduction}

Dyke-Davidoff-Masson Syndrome (DDMS) was first described in 1933 (1). Slon et al. (2) reported a case who is a historical patient is the 6000 year-old skeleton of an adult male with DDMS; however, they presume the diagnosis based on only radiological calvarial findings without any clinical findings. The clinical features of DDMS include seizures, mental retardation, facial asymmetry and sensorineural hearing loss. The radiological features are unilateral loss of cerebral volume dilation of the ipsilateral lateral ventricle, and associated compensatory bone alterations in the calvarium, like thickening, hyperpneumatisation of the paranasal sinuses and mastoid air cells (1). Although some cases of the coexistence of multiple intracranial pathologies have been reported, the simultaneous occurrence of an epidermoid tumour and an arachnoid cyst in the same patient with DDMS has not been reported.

\section{Case Report}

A 35-year-old female was admitted to our hospital with seizures, headache and progressive weakness of right side of body. In her history, it was noted that she was born at home without any medical assistance. She had suffered right hemiparesis since birth and her seizures started at the age of 2 . Her epilepsy was well controlled with oral anti-epileptic drug therapy. Neurological examination showed right mild hemiparesis with diminished superficial sensation of the right side of her body. Additionally, she had moderate level of mental retardation.

Cranial CT showed left cerebral hemispheric atrophy with mild dilatation of the left lateral ventricle. Enlargement of frontal sinus and thickening of the calvarial bones were also seen on the left side. Furthermore, hypodense cystic lesions were detected in the left temporal fossa and inter-hemispheric region (Figure 1). Inter-hemispheric lesion was hypointense to grey matter and slightly hyperintense to Cerebrospinal fluid (CSF) on T1 weighted Magnetic Resonance (MR) images, and it appeared hyperintense to both grey matter and CSF on T2 weighted MR images. Restricted diffusion was evident on diffusion-weighted images (DWI) and apparent diffusion co-efficient (ADC) images. There was no contrast enhancement. A cystic lesion in the temporal fossa appeared hypointense on T1 weighted MR images and hyperintense on T2 weighted MR images. There was no contrast enhancement and very high $A D C s$ were demonstrated and appeared similar to cerebrospinal fluid (CSF) on DWI (Figures 2 and 3).

DDMS was diagnosed with these clinical and radiologic findings. The patient was operated on using a microsurgical technique for inter-hemispheric lesions. Histopathological examination of the lesion revealed an epidermoid tumour. The follow-up of the patient is being continued due to an arachnoid cyst.

\section{Discussion}

DDMS is generally classified into congenital and acquired varieties. The congenital type, in contrast to the acquired 


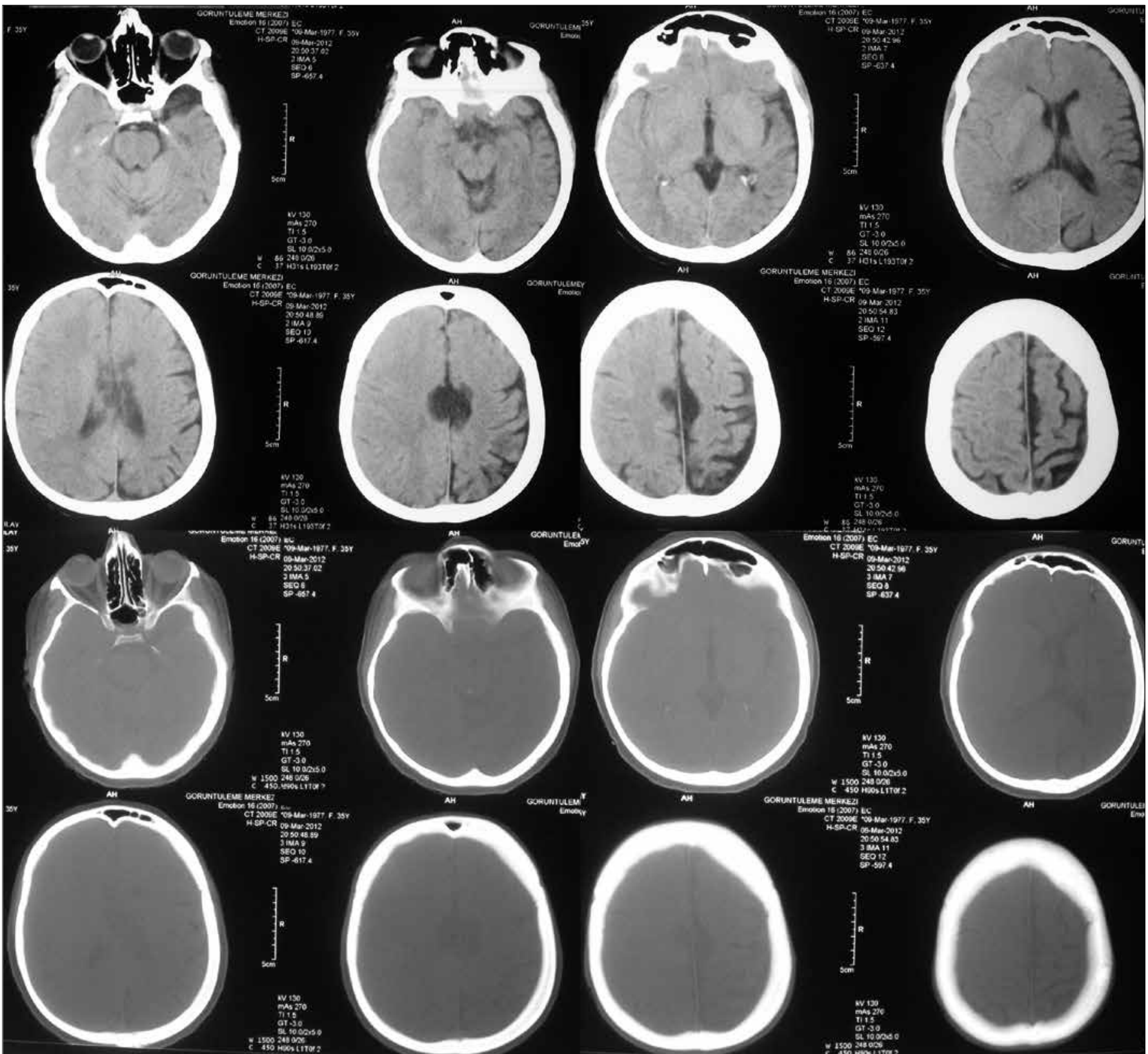

Figure 1. Plain axial CT scans showed thickness of the calvarium and enlargement of the frontal sinus on the left side, as well as hypodense cystic lesions in the inter-hemispheric region and left temporal fossa.

type, shows enlargement of the calvarium, diploic space and paranasal sinuses. These compensatory cranial changes occur to take up the relative vacuum created by the atrophied cerebral hemisphere. Symptoms appear at birth or shortly thereafter in the congenital type. The age of presentation depends on the time of insult and characteristic changes may be seen only in adolescence or adulthood in the acquired type (3). We considered our case congenital as the patient had no previous history of disease that may have been involved in the aetiology of DDMS; also, the radiological findings suggest a diagnosis of DDMS.

Patients with DDMS usually present with refractory seizures and their treatment should focus on control of the seizures with suitable anticonvulsants; sometimes, multiple anticonvulsants are used in combination. Prognosis is better if the onset of hemiparesis is after 2 years of age and in the absence of prolonged or recurrent seizure (4). In our case, she had suffered right hemiparesis since birth and her seizures started at the age of 2; the patient's epilepsy was well controlled with oral anti-epileptic drug therapy.

Epidermoid tumours are slow growing benign cysts of ectodermal origin that have well-characterised histology and contents consisting of desquamated keratin, cell debris and cholesterol clefts. They account for approximately $0.5-1.8 \%$ of all intracranial tumours (5). Epidermoid tumours are often located at the pontocerebellar angle, but rarely occur in the inter-hemispheric region and few cases have been reported in 


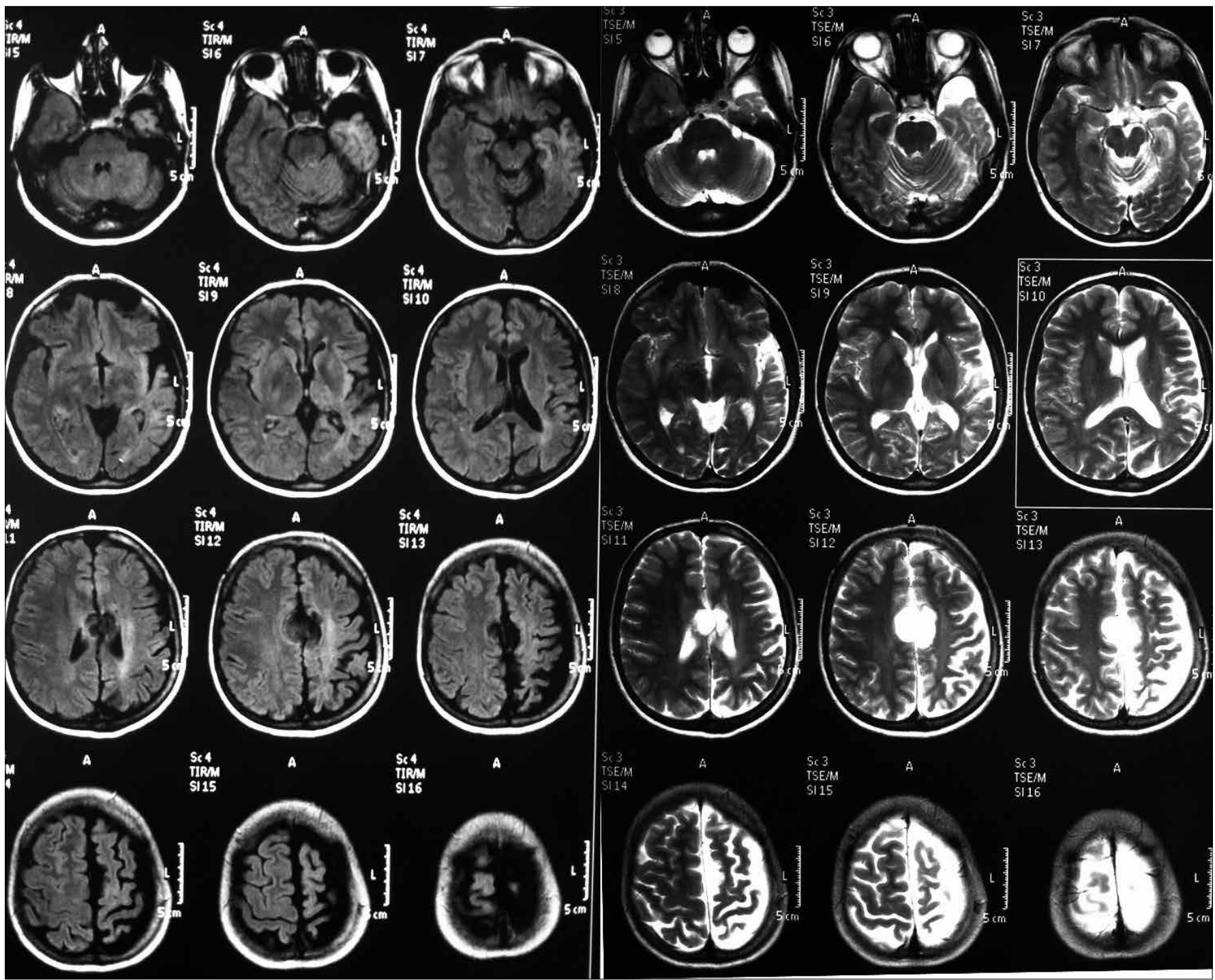

Figure 2. T1 and T2 weighted MR Images showed left cerebral hemispheric atrophy with mild dilatation of the left lateral ventricle and extraaxial CSF-like cyst in the left temporal fossa and the inter-hemispheric region.

the literature (6). Computed tomography scanning and magnetic resonance imaging are both helpful in the diagnosis of epidermoid tumours. MRI appears to be the best modality for radiological evaluation of these tumours. Typically, epidermoid tumours are hypointense on T1-weighted and hyperintense on T2-weighted images with long relaxation times. Enhancement of portions of the rim may be seen after the administration of contrast material. DWI is used to differentiate epidermoid tumours from arachnoid cysts. Epidermoid tumours have markedly restricted diffusion and, therefore, high signal intensity on the DWI. Similarly, intracranial arachnoid cysts are considered to be congenital malformations with a predilection for temporal fossa. We detected an uncommon case of DDMS with inter-hemispheric epidermoid tumour and arachnoid cyst in temporal fossa, compatible with the radiological findings $(7,8)$.

The simultaneous coexistence of multiple intracranial pathologies is very rare and their coexistence is not well understood. These conditions are especially associated with congenital genetic syndromes like Neurofibromatosis (9). Guzel et al. (10) described a syndrome of pachygyria, mental retardation and arachnoid cysts that is genetically transmitted. The coexistence of an arachnoid cyst and epidermoid tumours is very rare, however, and only one patient has been reported in the literature (11). To the best of our knowledge, this is the first case in the literature which has been seen DDMS associated with epidermoid tumour and arachnoid cyst.

In conclusion, any patient who receives DDMS in the light of clinical and radiological findings should be investigated for concomitant pathologies. Different sequences of MRI like DWI may be useful in the diagnosis of multiple intracranial lesions. 


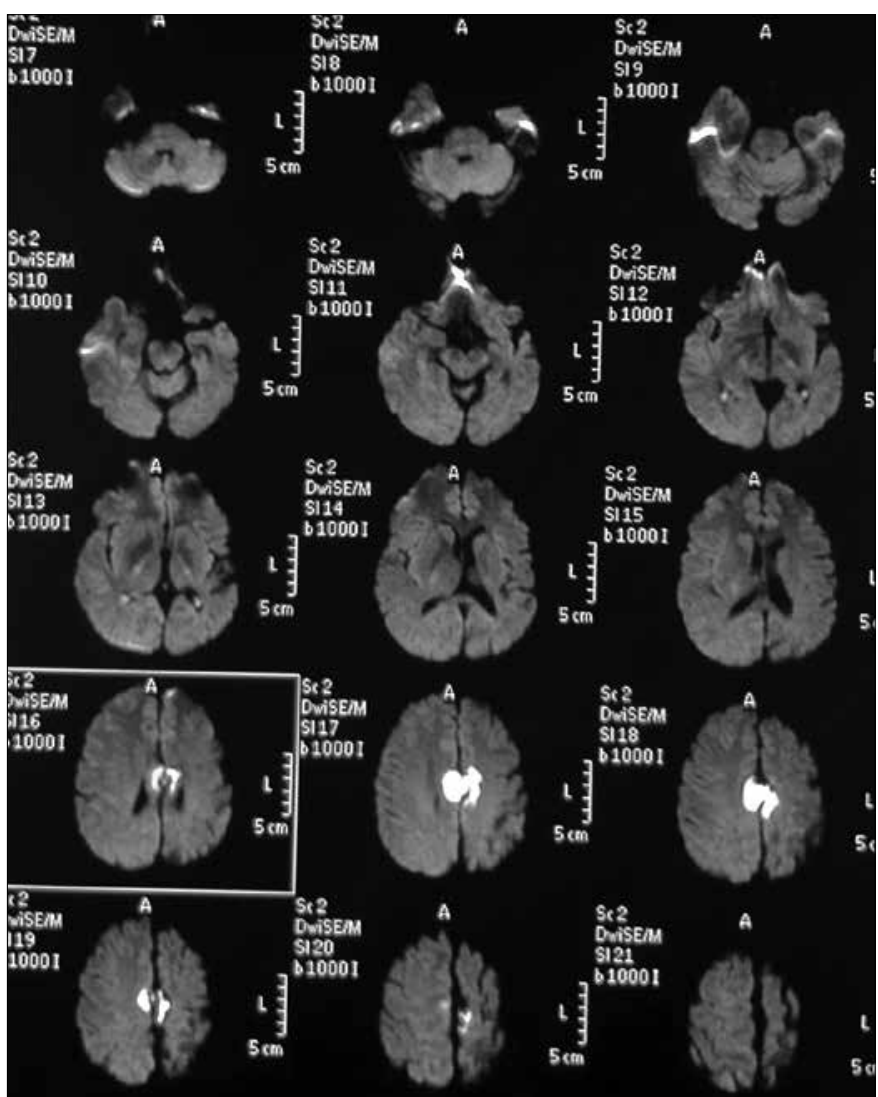

Figure 3. Axial DWI MR showed markedly restricted diffusion in the inter-hemispheric region and no restriction in the left temporal fossa.

Ethics Committee Approval: N/A.

Informed Consent: Written informed consent was obtained from the patient who participated in this study.

Peer-review: Externally peer-reviewed.

Author contributions: Concept - G.M., K.M.O.; Design - G.M., T.A.; Supervision - A.I.O., A.G.; Data Collection \&/or Processing - G.M.,
K.M.O.; Analysis \&/or Interpretation - G.M., T.A.; Literature Search G.M., K.M.O.; Writing - G.M., A.I.O.; Critical Reviews - G.M., A.I.O

Conflict of Interest: No conflict of interest was declared by the authors. Financial Disclosure: No financial disclosure was declared by the authors.

\section{References}

1. Dyke CG, Davidoff LM, Masson CB. Cerebral hemiatrophy with homolateral hypertrophy of the skull and sinuses. Surg Gyn Obstet 1933; 57:588-600.

2. Slon V, Hershkovitz I, Peled N. Dyke-Davidoff-Masson syndrome in 6,000-year-old skull. Neuroradiology 2012;54:1413-5. [CrossRef]

3. Aguiar PH, Liu CW, Leitão H, Issa F, Lepski G, Figueiredo EG, et al. MR and CT imaging in the Dyke-Davidoff-Masson syndrome. Report of three cases and contribution to pathogenesis and differential diagnosis. Arq Neuropsiquatr 1998;56:803-7. [CrossRef]

4. Pendse NA, Bapna P, Menghani V, Diwan A. Dyke-Davidoff-Masson Syndrome (DDMS). Indian J Pediatr 2004;71:943. [CrossRef]

5. McLendon RE. Epidermoid and Dermoid tumors: Pathology. In: Wilkins RH, Rengachary SS, editors. Neurosurgery. New York: McGraw-Hill 1996; pp.959-63.

6. Bhat DI, Devi BI, Raghunath A, Somanna S, Chandramouli BA. Interhemispheric epidermoids- An uncommon lesion in an uncommon location: A report of 15 cases. Neurol India 2011;59:82-6. [CrossRef]

7. Hakyemez B, Yildiz H, Ergin N, Uysal S, Parlak M. Flair and diffusion weighted MR imaging in differentiating epidermoid cysts from arachnoid cysts. Tani Girisim Radyol 2003;9:418-26.

8. Osborn AG, Preece MT. Intracranialcysts: radiologic-pathologic correlation and imaging approach. Radiology 2006;239:650-64. [CrossRef]

9. Mulvihill JJ, Parry DM, Sherman JL, Pikus A, Kaiser-Kupfer MI, Eldridge R. NIH conference. Neurofibromatosis 1 (Recklinghausen disease) and neurofibromatosis 2 (bilateral acoustic neurofibromatosis). An update. Ann Inter Med 1990;113:39-52. [CrossRef]

10. Guzel A, Tatli M, Bilguvar K, Diluna ML, Bakkaloglu B, Ozturk AK, et al. Apparently novel genetic syndrome of pachygyria, mentalretardation, seizure, and arachnoid cysts. Am J M Genet A 2007;143:672-7. [CrossRef]

11. Kasliwal MK, Fraser JF, Greenfield JP, Schwartz TH. Simultaneous middle fossa arachnoid cyst and ambient cistern epidermoid cyst: case report and endoscope-assisted microsurgical management. Pediatr Neurosurg 2010;46:151-4. [CrossRef] 